\title{
Studying the impact of technological factors on the productivity of grooved sorting with an auger intensifier
}

\author{
Kondratiev A.V., Rusinkevitch V.A. \\ Construction, road machinery and equipment dept. \\ Tver State Technical University \\ Tver, Russia \\ avkondr@yandex.ru
}

\author{
Antsev V.Y. \\ Hoisting and Conveying Machines and equipment dept. \\ Tula State University \\ Tula, Russia \\ anzev@yandex.ru
}

\author{
Kirichek A.V. \\ University administration \\ Bryansk State Technical University \\ Bryansk, Russia
}

\begin{abstract}
The article presents the results of the influence of technological factors on the efficiency and time of the gravel screening process on the roller grooved sorting with an auger intensifier. The article obtains the dependences of the efficiency of the gravel separation on the material feed to the sieve, the rotation direction of the auger, the rate of the gravel feed and the composition of the original mixture. The article reasons the technological parameters of the grooved screen, providing the highest rates of fractionating stone materials. The expediency of the selected technological characteristics is proved. It is based on the example of the obtained dependences of the efficiency and specific productivity of the screening process on the rate of the material feed with the most rational structural and kinematic parameters of the grooved sorting with an auger intensifier.
\end{abstract}

Keywords-grooved roller sorting; auger intensifier; material feed; the direction of the material transportation, the efficiency and time of the screening; gravel.

\section{INTRODUCTION}

In the production of non-metallic building materials, the processes of fractionating sand, gravel and crushed stone occupy a significant amount of operations in preparing the final product. Therefore, currently many researchers are working on improving the sorting devices, providing high levels of quality and performance processes for separating and screening granular mixtures [1-10].

The results of earlier studies have shown a sufficiently high efficiency of the grooved roller with an auger intensifier in the classification of stone materials. This device is a kind of the known roll sorting schemes for separating bulk materials and in particular for fractionating gravel and crushed stone $[11,12]$.

The grains of the material move on the grooved surface of the sieve along the rotating shafts with the discs along a zigzag path. They constantly move up and down the side of the groove. Such complex movement of the material contributes to the intensive mixing of the material particles and their distribution on the surface of the sieve. Thereby it creates favorable conditions for sifting fine grains of gravel and crushed stone in the intervals between the discs and shafts. It is obvious that in order to achieve high results in fractionating mixtures along with the structural and kinematics parameters of the device it is necessary to take into account the technological characteristics of the screening process. The technological parameters of the grooved device include: the rate of the material feed to the sieve; the composition of the initial mixture that is the correlation of the lower and upper classes; the method of feeding the material to the groove from the end to the middle shafts of the groove, from above or below to the lower shafts of the groove in the direction of rotating the discs; the direction of rotation of the auger intensifier is in the direction of the discs rotation or towards the discs rotation.

\section{THE DESCRIPTION OF THE DEVICE AND THE PARAMETERS OF THE EXPERIMENT}

To determine the influence of technological factors of the process of fractionating gravel on the grooved sorting with an auger intensifier, experimental researches were carried out on the bench equipment. It had the following characteristics: the number of shafts was 5 , the shaft length was $600 \mathrm{~mm}$; the shaft diameter was $50 \mathrm{~mm}$, the distance between the axes of adjacent shafts was $240 \mathrm{~mm}$; the disc shape is octagonal, the disc diameter was $340 \mathrm{~mm}$; the disc thickness was $8 \mathrm{~mm}$; the gap between the adjacent discs of the shaft was $30 \mathrm{~mm}$; the diameter of the auger intensifier was $920 \mathrm{~mm}$; the pitch of winding of the auger intensifier was $230 \mathrm{~mm}$; the width of the screening surface was $900 \mathrm{~mm}$. The longitudinal angle of the groove (the angle of the shaft) during the movement of the 


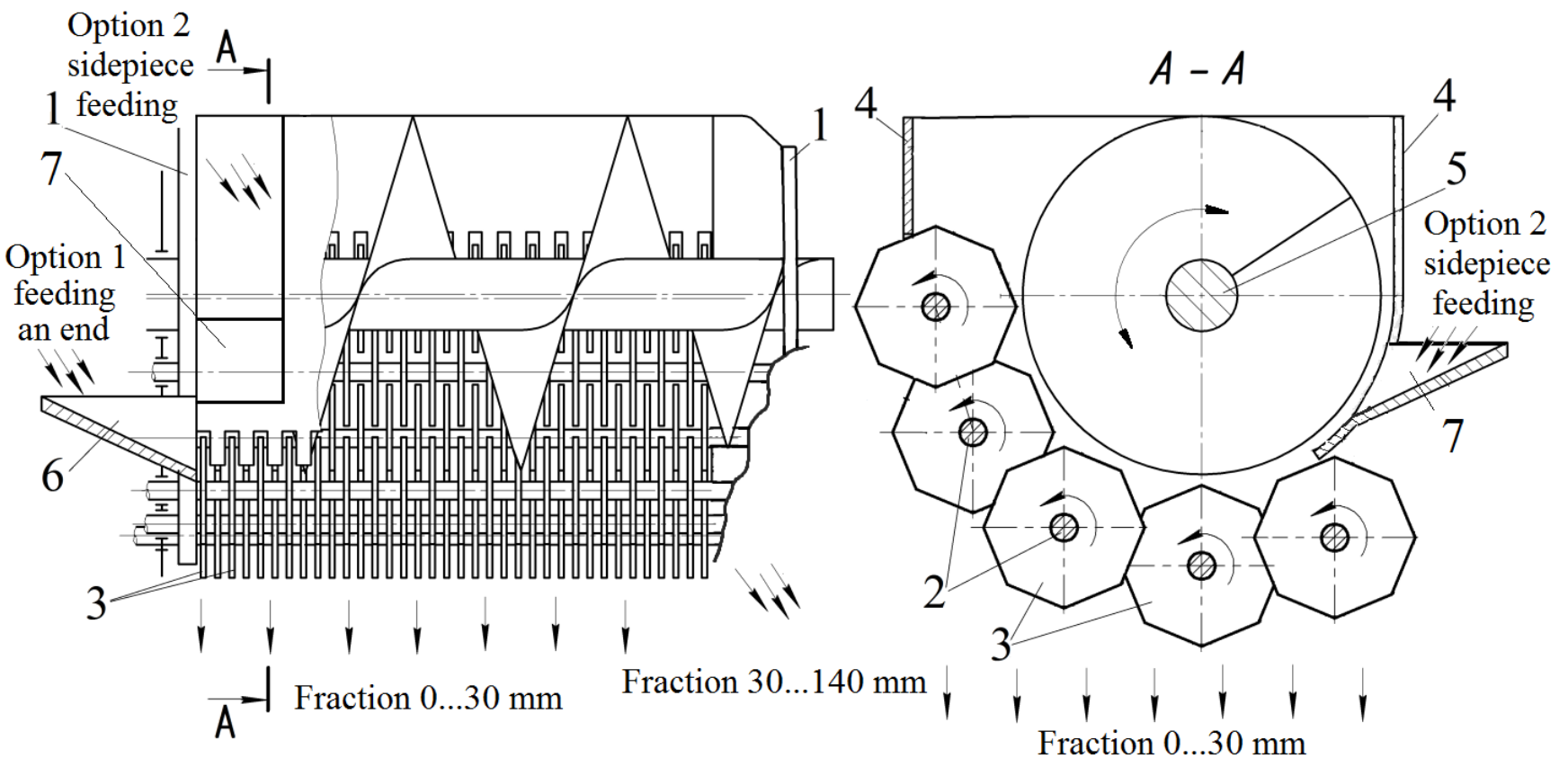

Fig. 1. The scheme of grooved screen with an auger intensifier: 1 - frame; 2 - shaft; 3 - wheels; 4 - stationary casings; 5 - the auger; 6 -boot tray

material was $\left(-2^{\circ}\right)$. The transverse installation angle of the upper shaft relative to the previous one was equal to $\left(+60^{\circ}\right)$ (the greatest steepness of the surface of the groove), the frequency of rotation of the shafts with the discs is 129 $\mathrm{rev} / \mathrm{min}$, the rotation frequency of the auger is $46 \mathrm{rev} / \mathrm{min}$. The material feed to the roller sieve was changed in the range of $90 \ldots 630 \mathrm{~kg} / \mathrm{min}$. The material was fed to the screen from the belt conveyor having the following specifications: the length of the belt conveyor was $1.3 \mathrm{~m}$, the width of the belt was 0.2 $\mathrm{m}$; the speed of the belt was $0.17 \mathrm{~m} / \mathrm{s}$.

The scheme of grooved roller screen with an auger intensifier is given in Fig. 1. It shows the methods of feeding the material to the groove and the direction of the auger rotation. The device consists of frame 1, on which the longitudinal shafts 2 with the discs 3 are fixed. They form a grooved screening surface. Fixed casings 4 are installed at the upper and lower shafts 2 on frame 1. Their lower part is made in the form of a comb, entering the intervals between the discs 3 . The auger 5 with elastic blades is installed over the shafts 2 with the discs 3 on the frame 1 along the groove. The drive axis with the discs and the fixed casings are located along the circumference which is concentric with the circumference of the auger, with a gap to the latter. The loading tray 6 is installed on the side of the feed of the separated material from the end of the groove. The loading tray 7 is installed on the side of the groove. A discharge window is made at the end of the groove on the frame 1 between the shafts 2 for unloading a large fraction of the material.

\section{THE RESULTS AND DISCUSSION}

Table 1 presents the dependence of efficiency of screening stone material on the feed of the material to the groove when the gravel is fed from the end (option 1, fig. 1) and side (option 2, fig. 1). The results show an obvious advantage of feeding the gravel to the sieve from the end, when the screening efficiency was $5 \ldots 15 \%$ higher compared to the feeding the gravel from the side. This is due to the more rapid distribution of the material on the surface of the sieve. In this case it is fed from the end to the middle shafts, when immediately at the beginning of the groove, the part of the material was picked up by the blades of the groove and rotating discs and was headed to the zone of the upper shafts and the other part rolled down the rotating discs.

TABLE I.

THE DEPENDENCE OF THE EFFICIENCY OF THE SCREENING ON THE MATERIAL FEED

\begin{tabular}{|c|c|c|c|c|}
\hline \multirow[t]{2}{*}{ Indicators } & \multicolumn{4}{|c|}{$\begin{array}{l}\text { The rate of the gravel to the groove } q \text {, } \\
\qquad \mathrm{kg} / \mathrm{min}\end{array}$} \\
\hline & 90 & 270 & 450 & 630 \\
\hline $\begin{array}{l}\text { The efficiency of the } \\
\text { screening } \\
\% \text { (feed from the end) }\end{array}$ & 80,16 & 88,58 & 89,31 & 89,71 \\
\hline $\begin{array}{l}\text { The efficiency of the } \\
\text { screening } \\
\% \text { (feed from the side) }\end{array}$ & 74,49 & 72,16 & 74,09 & 74,49 \\
\hline
\end{tabular}

Dynamics of screening the gravel along the length of the groove is shown in table 2 (the feed of the material is 630 $\mathrm{kg} / \mathrm{min}$ ). Table 2 shows that when the gravel was fed from the end, the particles were sifted more intensively along the length of the sieve. Most of the gravel was sifted on the first section of the groove, and the remaining part was sifted on the second and third sections. When the gravel was fed from the side, the bulk of the particles were sifted on the first and second sections of the screen. Most of the particles were sifted on the second section, which indicates a less intensive distribution of the gravel on the surface of the sieve. 
TABLE II.

SIFTING GRAVEL ALONG THE LENGTH OF THE GROOVE

\begin{tabular}{|l|c|c|c|c|}
\hline \multirow{2}{*}{ Indicators } & \multicolumn{4}{|c|}{ The Length of the grooved surface, mm } \\
\cline { 2 - 5 } & $\mathbf{7 5 0}$ & $\mathbf{2 2 5 0}$ & $\mathbf{3 7 5 0}$ & $\mathbf{5 2 5 0}$ \\
\hline $\begin{array}{l}\text { The rate of the sifted gravel, } \\
\mathrm{kg} \text { (feed from the end) }\end{array}$ & 32,93 & 7,73 & 1,11 & 0,17 \\
\hline $\begin{array}{l}\text { The rate of sifted gravel, } \\
\mathrm{kg} \text { (feed from the side) }\end{array}$ & 13,43 & 15,63 & 4,03 & 1,05 \\
\hline
\end{tabular}

TABLE III.

SIFTING GRAVEL ACROSS THE WIDTH OF THE GROOVE

\begin{tabular}{|l|c|c|c|c|c|c|}
\hline \multirow{2}{*}{ Indicators } & \multicolumn{6}{|c|}{ The length of the grooved surface, mm } \\
\cline { 2 - 7 } & $\mathbf{7 5 0}$ & $\mathbf{2 2 5 0}$ & $\mathbf{3 7 5 0}$ & $\mathbf{5 2 5 0}$ & $\mathbf{6 7 5 0}$ & $\mathbf{8 2 5 0}$ \\
\hline $\begin{array}{l}\text { The rate of the sifted gravel, } \\
\mathrm{kg} \text { (feed from the end) }\end{array}$ & 1,96 & 3,62 & 9,87 & 9,91 & 7,71 & 4,12 \\
\hline $\begin{array}{l}\text { The rate of the sifted gravel, } \\
\mathrm{kg} \text { (feed from the side }\end{array}$ & 5,74 & 5,84 & 9,76 & 5,54 & 2,79 & 1,94 \\
\hline
\end{tabular}

Table 3 shows the distribution of the gravel sifting through the width of the groove. Upon feeding the material on the lower shaft of the groove (feed from the side), the gravel was gradually distributed over the width of the sieve, and the most part of it was sifted on the lower and middle shafts of the device. And when the gravel was fed from the end, most of the particles were sifted on the middle and upper shafts of the groove. This distribution of the material was due to the capture by the blades of the auger the gravel grains from the middle part of the groove (the zone of the material feed), followed by their direction to the upper shafts. This, in turn, provided a more intensive passage of the material particles in the sieve holes in the first section of the groove along its length. Based on the analysis of the data obtained, the material feed from the end (option 1, fig. 1) can be considered the most rational.

Table 4 shows the influence of the direction of the auger rotation on the efficiency of screening the particles. Upon rotating the auger in the direction of the discs rotation (feeding the material by the auger blades down the side of the groove) there is an increase in the concentration of the gravel grain in the bottom of the sieve. It hinders the passage of small particles in the screening window. Therefore, screening efficiency remained virtually unchanged in the range of $80 \ldots$ $82 \%$ in the entire range of the material feed during its transporting by the auger down the groove. Transporting the same material by the auger blades up the side of the groove

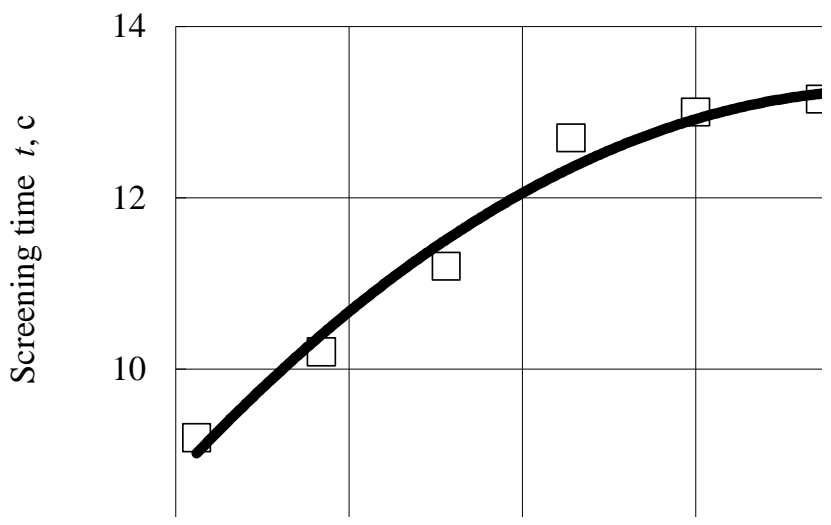

Fig. 2. The effect of the material feed on the time of the screening process (transporting gravel by the groove in the direction of the disks rotation) (the rotation of the groove in the direction of the discs rotation) provided a fairly good distribution of the gravel on the surface of the sieve and led to an increase in the efficiency of the screening from 80 to $90 \%$. At this feeding the separated mixture increased from 90 to $630 \mathrm{~kg} / \mathrm{min}$.

TABLE IV.

THE DEPENDENCE OF THE EFFICIENCY OF THE SCREENING ON THE MATERIAL FEED

\begin{tabular}{|c|c|c|c|c|}
\hline \multirow[t]{2}{*}{ Indicators } & \multicolumn{4}{|c|}{$\begin{array}{l}\text { The rate of the gravel feed to the } \\
\text { groove } \mathrm{q} \text {, } \\
\mathrm{kg} / \mathrm{min}\end{array}$} \\
\hline & 90 & 270 & 450 & 630 \\
\hline $\begin{array}{l}\text { The efficiency of the screening E, } \\
\% \text { (transporting the gravel } \\
\text { by the groove in the } \\
\text { direction of the discs rotation) }\end{array}$ & 80,16 & 88,58 & 89,31 & 89,71 \\
\hline $\begin{array}{l}\text { The efficiency of the screening E, } \\
\% \text { (transporting the gravel } \\
\text { by the groove towards } \\
\text { the discs rotation) }\end{array}$ & 81,25 & 80,85 & 80,51 & 81,17 \\
\hline
\end{tabular}

Fig. 2 shows the change in the time of the process of the gravel screening on the grooved sorting with an auger intensifier depending on the rate of the stone material feed. The presented data show an increase in the time of the gravel separation process with an increase of its supply to the sieve. Moreover, at first there was a noticeable increase in the time of screening with an increase in the feed from 90 to 360 $\mathrm{kg} / \mathrm{min}$. Then the time factor became almost constant in the range of feeds from $450 \ldots 630 \mathrm{~kg} / \mathrm{min}$. This is explained by a fairly good distribution of the material on the sifting surface, whereby the time of the screening process does not increase with simultaneously high efficiency.

At the final stage of the research the authors studied the influence of the composition of the initial mixture (the ratio of the lower and upper classes) on the qualitative indicators of the gravel fractionation process. The obtained data (table 5) show a general increase in the efficiency of screening with an increase in the percentage of the incoming material of lowerfraction grains. It does not contradict the generally accepted ideas about the classification process. At the same time, it should be noted that with an increase in the content of the lower class particles in the initial material from 15 to $45 \%$, a significant increase in the efficiency of screening (about 10\%), was observed and a further increase from 45 to $90 \%$ didn't provide any noticeable effect on the efficiency of the particle separation. This indicates the stabilization of the fractionation process, when the particles of the upper class practically do not prevent the sifting of small gravel grains in the holes of the roller sieve.

TABLE V. THE DEPENDENCE OF THE EFFICIENCY AND THE TIME OF THE GRAVEL SCREENING ON THE PERCENTAGE OF THE CONTENT IN THE INITIAL MATERIAL OF THE LOW CLASS GRAINS

\begin{tabular}{|l|c|c|c|c|c|c|}
\hline \multirow{2}{*}{ Indicators } & \multicolumn{6}{|c|}{$\begin{array}{c}\text { Contents of the lower class grains } \\
\text { in the initial material, \% }\end{array}$} \\
\cline { 2 - 7 } & $\mathbf{1 5}$ & $\mathbf{3 0}$ & $\mathbf{4 5}$ & $\mathbf{6 0}$ & $\mathbf{7 5}$ & $\mathbf{9 0}$ \\
\hline $\begin{array}{l}\text { The efficiency } \\
\text { of the screening E, \% }\end{array}$ & 82,2 & 83,7 & 90,65 & 91,15 & 90,16 & 89,72 \\
\hline $\begin{array}{l}\text { The time } \\
\text { of the screening } t, c\end{array}$ & 11,6 & 12,05 & 12,71 & 12,73 & 12,81 & 12,88 \\
\hline
\end{tabular}


Further the studies were carried out with the gravel material, the fractional composition of which consisted of grains $5 \ldots 70 \mathrm{~mm}$. The initial mixture contained $60 \%$ of the lower and $40 \%$ of the upper classes. Taking into account the results of the preliminary experiments, the authors also defined the limits of the variation of the design parameters of the groove and kinematic parameters of the shafts with the discs and an auger intensifier. Their numerical values are presented in table 6 [13]. Therefore, subsequent experiments dealt with the selection of the rational numerical values of the roller sorting parameters that provide the highest efficiency and performance of the gravel screening process. In order to implement this task the experiments were carried out with an average rate of the material feed equal to $360 \mathrm{~kg} / \mathrm{min}$.

TABLE VI.

INTERVALS OF CHANGING THE CONSTRUCTIVE AND KINEMATIC PARAMETERS

\begin{tabular}{|l|c|c|c|c|c|}
\hline Parameters & \multicolumn{4}{|c|}{ Numerical values of the parameters } \\
\hline $\begin{array}{l}\text { The greatest steepness of } \\
\text { the groove } \mathrm{A}_{\max }, \text { degrees }\end{array}$ & $50^{\circ}$ & $55^{\circ}$ & $60^{\circ}$ & $65^{\circ}$ & $70^{\circ}$ \\
\hline $\begin{array}{l}\text { The longitudinal angle of } \\
\text { the groove } \gamma, \text { degrees }\end{array}$ & $0^{\circ}$ & $-2^{\circ}$ & $-4^{\circ}$ & $-6^{\circ}$ & $-7^{\circ}$ \\
\hline $\begin{array}{l}n-\text { the rotation frequency } \\
\text { of the shafts with the } \\
\text { discs, rpm }\end{array}$ & 70,4 & 84,7 & 105,7 & 126,7 & 141 \\
\hline $\begin{array}{l}n_{\text {aug }}-\text { the rotation } \\
\text { frequency of the auger, } \\
\text { rpm }\end{array}$ & 31 & 35 & 41 & 47 & 51 \\
\hline
\end{tabular}

Table 7 presents the sequence of the changes in the efficiency and time of the screening process, depending on the transverse maximum angle of the grooved surface. At the same time, the rotation frequency of the shafts with the discs amounted to $105.7 \mathrm{rpm}$, the rotation frequency of the auger was $41 \mathrm{rpm}$.

TABLE VII

THE DEPENDENCE OF THE EFFICIENCY AND TIME OF SIFTING GRAVEL ON THE TRANSVERSE ANGLE OF THE UPPER SHAFT OF THE GROOVE TO THE PREVIOUS

\begin{tabular}{|l|c|c|c|c|c|}
\hline \multirow{2}{*}{ Indicators } & \multicolumn{5}{|c|}{ Gradient angle $\boldsymbol{\alpha}_{\max }$, degrees } \\
\cline { 2 - 6 } & $\mathbf{5 0}^{\circ}$ & $\mathbf{5 5}^{\circ}$ & $\mathbf{6 0}^{\circ}$ & $\mathbf{6 5}^{\circ}$ & $\mathbf{7 0}^{\circ}$ \\
\hline $\begin{array}{l}\text { The efficiency of } \\
\text { the screening } E, \%\end{array}$ & 97,64 & 98,45 & 98,76 & 98,61 & 98,12 \\
\hline $\begin{array}{l}\text { The screening time } \\
t, c\end{array}$ & 8,01 & 8,94 & 9,32 & 10,47 & 10,62 \\
\hline
\end{tabular}

The data from table 7 show that at first with an increase of the angle $\alpha_{\max }$ to $60^{\circ}$ the efficiency of the screening increases, and with an increase in the numerical value of the angle to more than $65^{\circ}$ there is a slight decrease in the index E. At the same time, with an increase of the angle $\alpha_{\max }$ from $50^{\circ}$ to $70^{\circ}$, the time of the screening process was constantly increasing, which is explained by the decrease in the speed of the material along the shafts of the groove. Taking into account the highest efficiency of screening, the angles $\alpha_{\max }=60^{\circ} \ldots 65^{\circ}$ can be considered the most rational. This speaks for the fact that the particles of the material are well distributed along the surface of the sieve, and the intensity of their passage in the intervals between the discs is maximum.
TABLE VIII. THE DEPENDENCE OF THE EFFICIENCY AND TIME OF SIFTING GRAVEL ON CHANGES IN THE LONGITUDINAL ANGLE OF THE GROOVE SHAFTS

\begin{tabular}{|l|c|c|c|c|c|}
\hline \multirow{2}{*}{ Indicators } & \multicolumn{5}{|c|}{ Gradient angle $\gamma$, degrees } \\
\cline { 2 - 6 } & $\boldsymbol{0}^{\circ}$ & $\mathbf{- 2}^{\circ}$ & $\mathbf{- 4}^{\circ}$ & $\mathbf{- 6}^{\circ}$ & $\mathbf{- 7}^{\circ}$ \\
\hline $\begin{array}{l}\text { The efficiency of } \\
\text { the screening } E \text {, } \%\end{array}$ & 98,73 & 99,31 & 99,28 & 98,66 & 98,35 \\
\hline $\begin{array}{l}\text { The time of the } \\
\text { screening } t, c\end{array}$ & 10,42 & 9,91 & 9,15 & 8,64 & 8,21 \\
\hline
\end{tabular}

Table 8 shows the results of studying the effect of the longitudinal angle of inclination of the shafts of the grooved surface on the efficiency and time of the gravel sifting process at $\mathrm{n}=105.7 \mathrm{rpm}$ and $\mathrm{n}_{\text {aug }}=41 \mathrm{rpm}$.

At first an increase in the efficiency of sifting the gravel grains in the range of $\gamma=0 \ldots\left(-2^{\circ}\right)$ was observed, with the increase in the angle of inclination of the groove shafts downwards in the direction of the movement of the separated mass. Then after the angle $\left(-4^{\circ}\right)$ there was a tendency to a decrease in the index $\mathrm{E}$ (table 8). In the entire range of changing angle $\gamma$ from 0 to $7^{\circ}$ there was a decrease in the time of the screening process due to increasing the speed of the material movement on the surface of the sieve. According to the data presented in table 8 , the angle interval $\gamma=\left(-2^{\circ}\right) \ldots\left(-4^{\circ}\right)$ can be considered the most preferable, because $\mathrm{E}>99 \%$.

Table 9 shows quantitative indicators of the efficiency and specific capacity of the fractionation process depending on the change in rotation frequency of the shafts with the discs at $n_{\text {aug }}$ $=41 \mathrm{rpm}$.

TABLE IX. THE DEPENDENCE OF THE EFFICIENCY AND SPECIFIC CAPACITY OF SIFTING GRAVEL ON THE ROTATION FREQUENCY OF THE SHAFTS WITH THE DISCS

\begin{tabular}{|c|c|c|c|c|c|}
\hline \multirow[t]{2}{*}{ Indicators } & \multicolumn{5}{|c|}{$\begin{array}{l}\text { The rotation frequency of the } \operatorname{discs} n \text {, } \\
\text { rpm }\end{array}$} \\
\hline & 70,4 & 84,7 & 105,7 & 126,7 & 141 \\
\hline $\begin{array}{l}\text { The efficiency of the } \\
\text { screening } E, \%\end{array}$ & 98,58 & 98,48 & 98,33 & 98,18 & 98,08 \\
\hline $\begin{array}{l}\text { Specific capacity } G_{s p}, \mathrm{t} / \\
\mathrm{m}^{2} \cdot \mathrm{h}\end{array}$ & 26,33 & 25,74 & 24,88 & 24,02 & 23,43 \\
\hline
\end{tabular}

The presented data show that with an increase in the rotation speed of the shafts with the discs, there is a gradual slight decrease in the efficiency of the gravel screening. This is explained by the fact that with increasing the speed of the shafts rotation, the flight time of the particles over the sieve surface increases due to the greater impact of the discs on the grains of the material. Therefore, the time spent on the material directly on the sieve is reduced. So, the probability of sifting fine particles is reduced. Taking into account the results of the screening efficiency, it can be concluded that the rotation frequency of the shafts with the discs in the range of $70.4 \ldots 84.7 \mathrm{rpm}$ is the most preferable.

The increase in the rotation frequency of the shafts with the discs causes a corresponding decrease in the intensity of sifting the fine fraction of the material. This is explained by an increase in the speed of going along the grooved sorting of the gravel grains that slip through the holes in the roller sieve (tab. 
9). As a result, subsequent studies were carried out at $n=70.4$ r/min.

Table 10 shows the nature of the change of $E$ and $G_{s p}$ depending on the increase in the rotation frequency of the auger.

TABLE $X . \quad$ THE DEPENDENCE OF THE EFFICIENCY AND SPECIFIC CAPACITY OF SCREENING THE GRAVEL ON THE ROTATION FREQUENCY OF THE AUGER

\begin{tabular}{|l|c|c|c|c|c|}
\hline \multirow{2}{*}{ Indicators } & \multicolumn{5}{|c|}{ The rotation frequency of the auger $\boldsymbol{n}_{\text {aug }}, \mathbf{r p m}$} \\
\cline { 2 - 6 } & $\mathbf{3 1}$ & $\mathbf{3 5}$ & $\mathbf{4 1}$ & $\mathbf{4 7}$ & $\mathbf{5 1}$ \\
\hline $\begin{array}{l}\text { The efficiency of the } \\
\text { screening } E, \%\end{array}$ & 98,99 & 98,83 & 98,58 & 98,33 & 98,17 \\
\hline $\begin{array}{l}\text { Specific capacity } G_{s p}, \\
\mathrm{t} / \mathrm{m}^{2} \cdot \mathrm{h}\end{array}$ & 27,22 & 26,86 & 26,33 & 25,79 & 25,44 \\
\hline
\end{tabular}

Changing the rotation frequency of the auger from $31 \mathrm{rpm}$ to $51 \mathrm{rpm}$ also leads to a slight decrease in the screening efficiency. This is due to increasing the linear velocity of the material along the sieve, so that the particles do not have any time to sift through in the intervals between the discs. The obtained data allow us to note the highest efficiency of the screening process at the auger speed of $31 \ldots 35 \mathrm{rpm}$.

The maximum specific capacity of the unit is observed in the range of the auger speed from $31 \mathrm{rpm}$ to $41 \mathrm{rpm}$. Expanding the limits of the rotation frequency of the auger up and down leads to a decrease in its performance.

The results of this study were to assess the dependence of the efficiency of the screening and the specific hourly productivity of the gravel sieving on the rate of the material feed to the grooved sorting. The technological characteristics, structural and kinematic parameters reasoned above [14] were taken into account. These constructive and kinematic parameters were the following: the transverse angle $\alpha_{\max }=$ $62^{\circ}$; the longitudinal angle $\gamma=\left(-3^{\circ}\right)$; the rotation frequency of the shafts with the discs $n=75 \mathrm{rpm}$; the rotation frequency of the auger $n_{\text {aug }}=33 \mathrm{rpm}$. The numerical values of the parameters were chosen on the basis of arguing their rational limits.

The results of the experimental data are presented in table 11, where one can observe a slight decrease in the efficiency of the screening process with an increase in the gravel feed to the roller sorting. However, in the whole range of the material feed to the sieve the efficiency of the screening was about $99 \%$, which confirms the validity of the adopted technological parameters of the roller sorting.

TABLE XI. THE DEPENDENCE OF THE EFFICIENCY AND SPECIFIC CAPACITY OF SIFTING GRAVEL ON THE MATERIAL FEED

\begin{tabular}{|l|c|c|c|c|c|c|c|}
\hline \multirow{2}{*}{ Indicators } & \multicolumn{6}{|c|}{ The rate of the gravel feed to the groove q, kg/ min } \\
\cline { 2 - 8 } & $\mathbf{9 0}$ & $\mathbf{1 8 0}$ & $\mathbf{2 7 0}$ & $\mathbf{3 6 0}$ & $\mathbf{4 5 0}$ & $\mathbf{5 4 0}$ & $\mathbf{6 3 0}$ \\
\hline $\begin{array}{l}\text { The efficiency } \\
\text { of the the } \\
\text { screening } E, \%\end{array}$ & 99,42 & 99,28 & 99,14 & 98,99 & 98,85 & 98,70 & 98,56 \\
\hline $\begin{array}{l}\text { Specific } \\
\text { capacity } G_{s p}, \mathrm{t} / \\
\mathrm{m}^{2} \cdot \mathrm{h}\end{array}$ & 10,84 & 17,18 & 22,64 & 27,23 & 30,95 & 33,78 & 35,75 \\
\hline
\end{tabular}

The change in the feed of the gravel material from 90 $\mathrm{kg} / \mathrm{min}$ to $630 \mathrm{~kg} / \mathrm{min}$ causes an increase in the specific capacity of the gravel sifting by more than three times, with a slight decrease in the screening efficiency from $99.42 \%$ to 98.56\% (table 11). This also confirms rather a high performance of the grooved sorting with an auger intensifier.

\section{CONCLUSION}

Thus, in the course of the research it was studied the impact of the technological factors on the performance of the process of the gravel screening for the grooved roller sorting. The rational method of feeding the material and the direction of its transportation by the auger is established. The material is fed from the end of the groove to its middle shafts, the material is fed by the auger up the side of the grooved sifting surface. The dependences of the efficiency and time of the screening process on the feed rate to the sieve of the stone material and its granulometric composition are determined. Taking into account the greatest efficiency indicators and specific capacity of the screening process, rational design and kinematic parameters of the separation device were justified. In addition, the dependences of the efficiency of screening and specific capacity of the sifted gravel were obtained for the entire range of the material feed to the separating device. At that, there were accounted the rational parameters of the transverse and longitudinal angles of inclination of the sifting surface, the rotation frequency of the shafts with the discs, the rotation speed of the auger intensifier. All this, in turn, confirmed the validity of choosing technological characteristics of the grooved sorting.

\section{References}

[1] V.A. Ogurtsov, A.P. Aleshina, E.R. Brik et al., "Improving the efficiency of bulk materials sieving on sieve woven fabrics", Physics of fibrous materials: structure, properties, science-intensive technologies and materials (SMARTEX), vol. 1, pp. 383-386, 2016.

[2] Yu.Yu. Bondarev, I.E. Zvonarev, S.L. Ivanov et al., "Reasoning the rational structure of modular fuel and energy autonomous complex on peat raw materials", Mining machinery and electromechanics, vol. 2 (111), pp. 29-35, 2015.

[3] S.V. Repin, S.A. Sizikov, and A.P. Skripilov, "Theoretical and experimental investigations of impact screen for sand fractionation", Vestnik grazhdanskikh inzhenerov (Vestnik of civil engineers), vol. 5 (40), pp. 188-193, 2013.

[4] M. Sugimoto, K. Yamamoto, and J.C. Williams, "Continuous separation of spherical and non-spherical particles on an inclined rotating disc", Journal of Chemical Engineering of Japan, vol. 10 (2), pp. 137-141, 1977.

[5] K. Yamamoto, T. Okumura, and M. Sugimoto, "The separation of irregularly shaped fine particles by a vibrating rotating disc", Advanced Powder Technology, vol. 9 (1), pp. 81-95, 1998.

[6] Y. You, M. Liu, H. Ma, L. Xu, B. Liu, et al., "Investigation of the vibration sorting of non-spherical particles based on DEM simulation", Powder Technology, vol. 325, pp. 316-332, 2018.

[7] I.I. Blekhman, L.I. Blekhman, L.A. Vaisberg, and V.B. Vasilkov, "Gradient vibratory segregation in loose materials size classification processes", Obogashchenie Rud, vol. 5, pp. 20-24, 2015.

[8] I.I. Blekhman, L.I. Blekhman, V.B. Vasilkov, and K.S. Yakimova, "The theory of gradient vibratory segregation effect as applied to screening process", Obogashchenie Rud, vol. 6, pp. 19-22, 2015. 
[9] A.N. Korovnikov, and V.A. Trofimov, "Upon the possibilities of dry disintegrated materials classification process intensification", Obogashchenie Rud, vol. 6, pp. 9-14, 2017.

[10] I.D. Ustinov, and T.M. Baldaeva, "Vibratory size classification. Thermodynamic model", Obogashchenie Rud, vol. 1, pp. 12-16, 2018.

[11] N.V. Mikhailov, O.Y. Bizyaev, and P.A. Spiridonov, "The roller type device for moist raw material classification", Ore benefication, vol. 4 (364), 2016. pp. 48-55.

[12] Yu.Yu. Bondarev, I.E. Zvonarev, S.L. Ivanov et al., "Rolling-disk separator of autonomous modular complex of extracting and processing peat raw materials for fuel", Vestnik of Perm National Research Polytechnic University. Geology. Oil, gas and mining, vol. 14, pp. 7381, 2015.

[13] A.V. Kondratyev, S.M. Kochkanyan, N.E. Vorobyev, A.I. Perunov, and V.A. Rusinkevich, "Studying the gravel screening process for the grooved roller sorting" Mechanization of construction, vol. 1. pp. 20-23, 2013.

[14] A.V. Kondratyev, and V.A., Rusinkevitch, "Determining rational parameters of the grooved gross screening with an auger +intensifier", Construction and road machines (Stroitelnye i dorozhnye mashiny), vol. 9, pp. 45-47, 2015. 